\title{
A EMERGÊNCIA DO 'TERCEIRO MUNDO' E A QUESTÃO DA DESIGUALDADE NAS RELAÇÕES INTERNACIONAIS: RESPOSTAS TEÓRICAS A PARTIR DO NORTE E DO SUL GLOBAL
}

\author{
'THIRD WORLD' EMERGENCE AND THE ISSUE OF INEQUALITY IN INTERNA- \\ TIONAL RELATIONS: THEORETICAL ANSWERS FROM GLOBAL NORTH AND \\ SOUTH
}

Lucas Guerra ${ }^{1}$

\begin{abstract}
Resumo
O presente artigo tem por objetivo apresentar uma análise das respostas teóricas propostas a partir tanto do Norte quanto do Sul Global à questão da desigualdade internacional colocada em evidência a partir da emergência do 'Terceiro Mundo' na política internacional. A partir de uma metodologia essencialmente qualitativa, consistindo em revisão bibliográfica de autores do Norte e do Sul Global em Relações Internacionais e áreas correlatas, constatamos que as perspectivas desenvolvidas em cada um desses lugares epistêmicos apontam em direções opostas: as formuladas no Sul ressaltam a relação intrínseca entre a desigualdade e o funcionamento histórico/estrutural da economia internacional, enquanto que as formuladas no Norte propõem uma assimilação dos países terceiro-mundistas aos modelos de desenvolvimento próprio dos países industrializados ocidentais. Concluímos, assim, que o lugar geográficoepistêmico do sujeito teorizador influencia diretamente no resultado de suas análises e prescrições teóricas e políticas.
\end{abstract}

Palavras-Chave: Desigualdade Internacional; Sul Global; Norte Global; Geopolítica do Conhecimento; Teoria das Relações Internacionais.

\begin{abstract}
The present article aims to present an analysis of the theoretical responses proposed from both the North and the Global South to the issue of international inequality highlighted by the emergence of the 'Third World' in international politics. We depart from a qualitative methodology, based on the bibliographic revision of authors from the Global North and South in IR and similar areas, noting through this that the perspectives developed in each of these epistemic places point in opposite directions: those formulated in the South highlight the intrinsic relation between inequality and the historical / structural functioning of the international economy, while those formulated in the North countries propose an assimilation of the third world countries
\end{abstract}

\footnotetext{
${ }^{1}$ Mestrando em Relações Internacionais pelo Instituto de Relações Internacionais da Pontifícia Universidade Católica do Rio de Janeiro (IRI/PUC-Rio). Rio de Janeiro - Brasil. Email: lucaspxguerra@gmail.com. O presente trabalho foi realizado com apoio da Coordenação de Aperfeiçoamento de Pessoal de Nível Superior - Brasil (CAPES) - Código de Financiamento 001. O autor agradece aos revisores e pareceristas do artigo pelos comentários, sugestões e contribuições realizadas. Qualquer erro ou inconsistência, no entanto, são de inteira responsabilidade do autor.
} 
to the development models of the Western industrialized countries. We conclude, therefore, that the geographic-epistemic place of the theorizer directly influences in him/her analysis and theoretical and political prescriptions.

Key words: International Inequality; Global South; North Global; Geopolitics of Knowledge; International Relations Theory.

\section{INTRODUÇÃO}

No presente artigo, temos por objetivo apresentar uma reflexão acerca dos impactos causados pelo que aqui chamamos de 'emergência do Terceiro Mundo' na política internacional sobre a reflexão teórica no campo das Relações Internacionais (RI). Mais especificamente, situamos esse 'emergência do Terceiro Mundo' nas 'ondas de descolonização' deflagradas principalmente na Ásia e na África entre as décadas de 1940 e 1960. Ademais, focamos nas abordagens teóricas em $\mathrm{RI}$ concernentes à questão da desigualdade internacional, pelo efeito que a independentização de países terceiro-mundistas gerou tanto teórica quanto politicamente sobre essa questão.

Nosso argumento inicial é que a 'emergência do Terceiro Mundo' posicionou um desafio importante a alguns dos pressupostos centrais vigentes na teoria de RI naquele momento. Notamos ainda que esse desafio gerou respostas teóricas distintas nos chamados 'Norte' e 'Sul'2 Global. Dito isso, argumentamos então que essas respostas refletem as realidades sociopolíticas experenciadas em cada um desses espaços geográficos e 'lugares epistêmicos' naquele período. Nesse sentido, inserimos a discussão apresentada ao longo do artigo no marco das considerações do pensamento decolonial acerca da assim chamada "geopolítica do conhecimento"3 (Mignolo, 2004, p. 241-242). Grossíssimo modo, trata-se do entendimento de que:

[...] a 'história' do conhecimento está marcada geo-historicamente e tem um valor e um lugar de 'origem'. O conhecimento não é abstrato e deslocalizado. Pelo

\footnotetext{
${ }^{2}$ Compartilhamos aqui da perspectiva de Chandra Mohanty (2003, p. 226-227) acerca do uso de termos como "Terceiro Mundo" ou "Sul Global". Apesar de representarem generalizações muitas vezes grosseiras, são considerados marcos úteis para distinguir as desigualdades existentes entre segmentos sociais que se beneficiam do capitalismo global contemporâneo (majoritariamente presentes no "centro" ou "Norte") e aqueles que são sobremaneira marginalizados ou diretamente prejudicados pelas dinâmicas de funcionamento desse sistema (majoritariamente na "periferia", "Sul" ou "Terceiro Mundo"). Nesse artigo, esses termos serão utilizados intercaladamente, mas dentro dessa concepção de indicar atores privilegiados e desprivilegiados nas dinâmicas de reprodução e funcionamento de uma economia mundial capitalista e do sistema internacional.

${ }^{3}$ Consideramos a disciplina de RI como um espaço profícuo para as discussões acerca dessa "geopolítica do conhecimento". Ora, ainda na década de 1970, Stanley Hoffman (1977) identificou a disciplina como uma "ciência social americana". Mais contemporaneamente, buscando descentrar essa condição, Steve Smith (2000) clamou por uma maior consideração à produção de conhecimento em RI na academia europeia. Conhecimentos e debates produzidos em outros 'lugares de enunciação', notadamente em países do Sul Global, foram historicamente marginalizados no interior da disciplina. É recente o esforço mais comprometido em mudar essa condição, sendo um exemplo a coletânea International Relations and NonWestern Thought, editada por Robbie Shilliam (2011), e o convite de David Blaney e Arlene Tickner (2017) para um "projeto decolonial em Rl".
} 
contrário. [...] o conhecimento, como a economia, está organizado mediante centros de poder e regiões subalternas (Mignolo, 2002, p. 2, tradução nossa ${ }^{4}$ ).

Embora não caiba no escopo desse artigo uma discussão mais aprofundada sobre o conceito, utilizamos a "geopolítica do conhecimento" para ressaltar dois elementos principais. O primeiro, é que os lugares geográficos onde se produz o conhecimento são também 'lugares' epistêmicos (Mignolo, 2002, p. 2-3). O segundo é que esses 'lugares' são atravessados por múltiplas relações de poder historicamente constituídas, ressignificadas e reproduzidas, tais como o colonialismo, colonialidade, imperialismo, racismo, machismo, eurocentrismo, capitalismo. Tais entrelaçamentos de relações de poder, como argumenta Mignolo (2004, p. 241), influenciam diretamente sobre o tipo de conhecimento produzido em 'lugares' geográficos e epistêmicos específicos ${ }^{5}$.

Por um lado, como reconhece o próprio Mignolo (2004, p. 227-228), as abordagens à geopolítica do conhecimento geralmente fazem argumentos historicamente mais amplos, remontando ao colonialismo e imperialismo. Isso decorre em uma desatenção às especificidades de processos mais contemporâneos, dentre eles as 'ondas de descolonização' de meados do século XX (ibid.). Por outro lado, as abordagens aos efeitos dessas 'ondas' na política internacional notadamente se ocupam de seu impacto geopolítico, em termos de relações de poder entre os Estados ${ }^{6}$. Esse enfoque, contudo, resulta na desconsideração da dimensão geopolítica da produção de conhecimento nesse contexto. Dito isso, pretendemos avançar uma perspectiva que ressalte justamente as diferentes interpretações teórico-analíticas desenvolvidas no Norte e no Sul Global acerca da questão da desigualdade internacional, posta em evidência com os processos de descolonização deflagrados entre as décadas de 1940 e 1960.

Para avaliar essas questões, utilizamos uma metodologia essencialmente qualitativa, baseada em revisão bibliográfica de contribuições de autores tanto do Sul quanto do Norte Global na disciplina de Relações Internacionais e/ou em áreas correlatas (economia política internacional e direito internacional, por exemplo). Tal revisão consistiu na busca pelos argumentos centrais desses autores acerca da desigualdade internacional, principalmente face à emergência dos países do Terceiro Mundo na política mundial. Quanto à seleção dos autores estudados, buscamos priorizar autores com obras consideradas relevantes dentro das $\mathrm{Rl}$ no que tange aos debates sobre desigualdade dentro da disciplina. Procuramos também contemplar autores que produziram suas obras durante o próprio período histórico das descolonizações e independências terceiro-mundistas. Além disso, o recorte foi conduzido de modo a abranger autores daquelas

\footnotetext{
${ }^{4}$ No original: "[...] la 'historia' del conocimiento está marcada geo-históricamente y además tiene un valor y un lugar de 'origen'. El conocimiento no es abstracto y des-localizado. Todo lo contrario. [...] el conocimiento, como la economía, está organizado mediante centros de poder y regiones subalternas".

${ }^{5}$ Efetivamente, a análise da "geopolítica do conhecimento" apresentada por Mignolo (2002; 2004) e outros pensadores decoloniais é consideravelmente mais aprofundada do que essa exposição esquemática. $O$ ponto fundamental levantado com o uso do termo é que, com o advento da modernidade - e seu 'lado obscuro', a colonialidade - impôs-se uma dominação do dito 'conhecimento científico' moderno e europeu sobre todas as demais epistemes e formas de saber. Um dos principais objetivos do pensamento decolonial, portanto, é confrontar o conhecimento eurocêntrico moderno e abrir espaços para as outras formas de saber historicamente silenciadas por ele (Mignolo, 2004, p. 250-251).

${ }^{6}$ Um exemplo nesse sentido são os trabalhos de Robert Tucker (1977) e Stephen Krasner (1985), mais detalhadamente apresentados ao longo do artigo.
} 
geralmente apontadas como as três principais correntes teóricas em RI: o realismo (Tucker e Krasner), o liberalismo (Beitz, Bourguignon, Pogge e Rawls) e o marxismo (dos Santos, Gunder Frank e N'Krumah).

Quanto à organização do artigo, optamos por estruturá-lo em duas seções. Na primeira, abordamos os impactos que a 'emergência do Terceiro Mundo' com a 'onda de descolonizações' de 1940-1960 teve para a política internacional daquele período. Discutimos também o desafio colocado por esse fenômeno para os pressupostos básicos das teorias de RI à época dominantes. $\mathrm{Na}$ segunda seção, apresentamos brevemente as respostas teóricas propostas a partir do Norte e do Sul global para esse desafio, destacando as potencialidades e limitações de cada uma delas. Em seguida, concluímos com uma comparação entre as perspectivas formuladas em cada um desses lugares epistêmicos sobre a questão da desigualdade.

\section{A 'EMERGÊNCIA DO TERCEIRO MUNDO’ NA POLÍTICA INTERNACIONAL: DESAFIOS TEÓRICOS E POLÍTICOS}

Em sua avaliação da conjuntura internacional pós-Segunda Guerra Mundial - mais especificamente entre 1945 e 1955 - Arturo Escobar (2007, p. 77-78) destaca um processo de importante reconfiguração na organização mundial do poder e nas estruturas mundiais de produção ${ }^{7}$. Para o autor, uma característica fundamental desse processo foi a emergência do 'Terceiro Mundo' como conjunto de atores ineditamente relevantes no cenário internacional (Escobar 2007, p. 64).

Assim, enquanto a lógica bipolar da Guerra Fria se estruturava sobremaneira entre um 'Primeiro Mundo' composto por países industrializados capitalistas liderados pelos EUA e um 'Segundo Mundo' de países industrializados socialistas liderados pela URSS, o assim chamado 'Terceiro Mundo' aglutinava um conjunto de países com características diferentes (Escobar, 2007, p. 64). Tratavam-se de países localizados principalmente na África e na Ásia, e em menor medida na América Latina, com economias desindustrializadas e a maioria deles ainda em processo de independentização (ibidem).

Ainda segundo Escobar (2007, p. 64-65), nos primeiros momentos após a Segunda Guerra, os países terceiro-mundistas estiveram sobre influência mais direta de ambos os polos de poder da Guerra Fria. Não obstante, conforme os processos de independentização e descolonização foram avançando, esses países lograram uma maior articulação entre si. Assim, paulatinamente os países do Terceiro Mundo lograram construir alianças em torno de uma participação ativa e propositiva nos grandes foros da política internacional, trazendo para o debate agendas obliteradas pelas grandes potências da época (Leite 2011, p. 56).

\footnotetext{
${ }^{7}$ Para uma avaliação mais detalhada dessas reconfigurações e reestruturações, ver (ESCOBAR 2007, p. 65-77).
} 
De acordo com Patrícia S. Leite (2011, p. 56-59), a Conferência de Bandung — realizada em 1955 - foi um marco paradigmático nesse sentido. Nela, pela primeira vez os Chefes de Estado de países terceiro-mundistas ${ }^{8}$ se reuniram em encontro de cúpula sem a participação de representantes de países europeus, dos EUA ou da URSS (Leite 2011, p. 56). Na avaliação da autora, Bandung representou a afirmação de uma identidade própria dos países do Terceiro Mundo, à parte tanto do bloco capitalista quanto do socialista, com uma agenda coletiva distinta da estabelecida pelo paradigma bipolar (ibidem, p. 57). Nesse sentido:

Bandung reveste-se de extrema importância política. Sinaliza o associativismo de jovem grupo de países em prol de inserção internacional independente e autônoma, com base na identificação de interesses mútuos. Em que pesem diferenças em termos políticos, econômicos, sociais e culturais, unia-os o passado da dominação colonial [...]. Atraía-os o repúdio ao colonialismo e ao neocolonialismo, entendido como nova forma de controle econômico e intelectual. Pregavam, em lugar da dominação e exploração estrangeira, a independência e a liberdade de povos subjugados na Ásia e na África, defendendo o seu direito à autodeterminação. Advogavam, ainda, a igualdade de todas as raças, condenando a segregação racial e a discriminação. Acresce a preocupação com a defesa e o fortalecimento da paz e segurança internacionais. Os 29 países afroasiáticos entendiam que a lógica bipolar, longe de manter a estabilidade, gerava a insegurança, particularmente após o equilíbrio do terror alcançado pela posse das armas nucleares de ambos os pólos [sic], e incutia o medo de uma iminente guerra atômica que aniquilaria todas as nações (Leite 2011, p. 56-57).

Assim, Leite (2011, p. 58-59) sustenta que Bandung foi um importante primeiro esforço de articulação entre países terceiro-mundistas para reivindicar pautas comuns nas instâncias internacionais. No decorrer das décadas seguintes, novos países - especialmente os latinoamericanos - se uniram a tais esforços, e novos temas - com ênfase para o desenvolvimento econômico - passaram a compor as demandas ecoadas pelas vozes dos países do Terceiro Mundo (ibidem).

Outro fator relevante apontado pela autora é o fato de os países do Terceiro Mundo, após as 'ondas' de descolonização, passarem a consistir a maioria de votantes na Assembleia Geral das Nações Unidas (AGNU) (Leite, 2011, p. 61). Como resultado desses processos, Leite (2011, p. 61-69) menciona a criação da Conferência das Nações Unidas para o Comércio e o Desenvolvimento (UNCTAD, na sigla em inglês) e as reivindicações conjuntas em foros internacionais por uma Nova Ordem Econômica Internacional (NOEI) ${ }^{9}$, mais favorável aos interesses econômicos dos países não-industrializados. Subjacente a tais resultados, estava a enfatização feita pelos países terceiro-mundistas de sua condição de desigualdade perante aos países industrializados/desenvolvidos tanto na política quanto na economia internacional, e das

\footnotetext{
${ }^{8}$ No total, participaram representantes de 29 países africanos e asiáticos: Afeganistão, Arábia Saudita, Camboja, Ceilão (atual Sri Lanka), China, Costa do Ouro (atual Gana), Egito, Etiópia, Filipinas, Índia, Indonésia, Iraque, Irã, Japão, Jordânia, Laos, Líbano, Libéria, Líbia, Nepal, Paquistão, Sião, Síria, Sudão, Tailândia, Turquia, Vietnã do Norte, Vietnã do Sul e lêmen (GUITARD 1962, p. 33).

${ }^{9}$ Não é nossa intenção, no escopo desse artigo, discorrer amplamente a respeito dessas questões. Para uma contextualização mais completa acerca de em que consiste cada um desses esforços, entre outros no âmbito da Cooperação Sul-Sul, ver (LEITE 2011, pp. 59-77).
} 
mazelas econômicas e sociais internas decorrentes dessa desigualdade (Escobar 2007, p. 51-52; Leite 2011, p. 68).

Nesse sentido, Vendulka Kubálková e Albert Cruickshank (1981, p. 14-15) reforçam que a onda descolonizadora ocorrida entre as décadas de 1940-1960 foi um ponto de inflexão na política internacional. A partir desse marco, o sistema internacional tradicional teve seus limites involuntariamente expandidos: multiplicou-se a quantidade de Estados em condição de igualdade soberana e, portanto, aptos a fazer suas reivindicações nas instâncias internacionais (Kubálková; Cruickshank, 1981, p. 14-15). A evidenciação das diversas desigualdades existentes entre os Estados se tornou então questão central nos debates teóricos dentro da disciplina de Relações Internacionais e em algumas de suas áreas correlatas (ibidem).

$\mathrm{Na}$ avaliação dos autores, a importância do fenômeno político das independências e descolonizações para as $\mathrm{RI}$ foi principalmente em torno do desafio que colocou para o paradigma teórico à época dominante na disciplina: o realismo (Kubálková; Cruickshank, 1981, p. 30-31). Assim, Kubálková e Cruickshank (ibidem) apontam que o realismo é notadamente caracterizado pela reificação e 'naturalização' das desigualdades entre Estados. Isso porque essa abordagem teórica prioriza uma análise focada nas Grandes Potências do sistema internacional e em questões militares e securitárias. Países considerados 'mais fracos' e elementos sociais e econômicos que compõem o sistema internacional, portanto, geralmente são negligenciados pelas abordagens realistas (ibidem).

Sendo assim, a 'emergência do Terceiro Mundo' no sistema internacional, avançando a agenda da desigualdade como pauta importante na política mundial, foi inicialmente subestimada pelas abordagens realistas às RI. A profusão de Estados terceiro-mundistas como ampla maioria numérica no sistema internacional, com políticas externas não prioristicamente pautadas em questões militares, portanto, foi inicialmente rendida como insignificante para os grandes processos na política internacional. Nas palavras de Kenneth Waltz (1979, p. 72-73, tradução nossa ${ }^{10}$ ), um dos principais expoentes do (neo)realismo nas $\mathrm{RI}$, "seria [...] ridículo construir uma teoria da política internacional baseada na Malásia ou na Costa Rica. [...] Uma teoria geral da política internacional é necessariamente baseada nas Grandes Potências".

Igualmente, em outra das abordagens teóricas centrais às $\mathrm{RI}$ no período imediatamente após as 'ondas de descolonização' - o neoliberalismo institucional - a emergência do Terceiro Mundo foi inicialmente marginalizada. Assim, em uma das obras fundamentais dessa corrente teórica, Robert Keohane (1984, p. 6) apresenta uma proposta de explicação da política internacional assumidamente delimitada aos países com uma economia de mercado avançada. Ao priorizar esse enfoque, o autor negligencia a questão da desigualdade como relevante para se pensar na política internacional. Além disso, Keohane (1984) exclui de suas considerações acerca do "sistema internacional" a maioria dos atores que à época compunham esse sistema: países desindustrializados e recém-independentes na assim chamada 'periferia global'.

\footnotetext{
${ }^{10}$ No original: "It would be [...] ridiculous to construct a theory of international politics based on Malaysia and Costa Rica [...] A general theory of international politics is necessarily based in the Great Powers".
} 
Assim, temos por um lado a emergência de países do Terceiro Mundo na política internacional, como resultado das ondas de descolonizações e independências entre as décadas de 1940-1960. Essa emergência de países terceiro-mundistas levou a questão da desigualdade internacional a ser crescentemente pautada em grandes foros internacionais, em grande parte devido à articulação e ação conjunta entre esses países. Por outro lado, as abordagens teóricas centrais na disciplina de Relações Internacionais - notadamente o realismo, seguido do neoliberalismo institucional — inicialmente negligenciaram essa questão.

Ainda assim, tanto no campo realista quanto no neoliberal surgiram tentativas de responder aos desafios colocados pela evidenciação da desigualdade internacional como tema central para se pensar as Relações Internacionais. Outras abordagens teóricas - especialmente o marxismo - também se viram centralmente ocupadas por essa questão. Desse modo, distintas respostas ao 'desafio da desigualdade' foram desenvolvidas tanto no Norte quanto no Sul Global, a partir de variados matizes teóricos. Uma discussão mais aprofundada desse fenômeno é o que orienta a seguinte seção.

\section{O TERCEIRO MUNDO E A QUESTÃO DA DESIGUALDADE: RESPOSTAS TEÓRICAS NO NORTE E NO SUL GLOBAL}

Alguns dos primeiros esforços intelectuais de adereçar a questão da desigualdade internacional vieram de intelectuais do Norte Global. Dentre eles, aqui destacamos o teórico liberal W.W. Rostow (1974 [1959]) e sua versão da 'teoria da modernização'. De maneira sumária Rostow (1974, n.p. ${ }^{11}$ ) propõe que existe um modelo universal a ser seguido por todas os países em suas trajetórias rumo ao desenvolvimento, modernização e progresso. Tal modelo, composto por cinco etapas de desenvolvimento econômico, parte de um estágio 'primitivo' pré-capitalista e tem como ponto de chegada a consolidação de uma sociedade altamente industrializada e com padrões de consumo de massa, aos moldes dos EUA (Rostow, 1974).

Para tanto, seria necessária a adequação das sociedades a valores individualistas (empreendedorismo, competitividade, propriedade privada etc.) que, progressivamente, levariam à consolidação de instituições políticas e econômicas favoráveis ao desenvolvimento (Rostow, 1974). Sendo assim, a proposta de 'teoria da modernização' apresentada por Rostow foi submetida a forte escrutínio crítico, notadamente por teóricos de países do Terceiro Mundo. Dentre os principais pontos de crítica, estava o ahistoricismo dessa abordagem, que desconsideraria fatores como o colonialismo e o imperialismo para o 'subdesenvolvimento' dos países 'periféricos' (Krishna, 2009, p. 13-14). Outro era que essa teoria universalizava e propunha como ideal um modelo de 'desenvolvimento' político e econômico notadamente capitalista e ocidental, sendo portanto identificada como ferramenta ideológica das disputas da Guerra Fria (Escobar, 2007, p. 135-138).

${ }^{11}$ Paginação não disponível na versão consultada. 
Assim, como aponta Sankaran Krishna (2009, p. 14), uma das principais fontes de críticas à teoria da modernização de Rostow foram as abordagens marxistas desenvolvidas por autoras e autores do Sul Global. Tais perspectivas teóricas denunciaram a relação intrínseca entre o 'subdesenvolvimento' dos países terceiro-mundistas (ou periféricos) e o 'desenvolvimento' dos países do 'Primeiro Mundo' (ou centrais) (Dos Santos, 2011, p. 6-7). Além disso, identificaram que essa relação intrínseca é resultante de processos históricos deflagrados com o advento e expansão do capitalismo enquanto sistema econômico mundial, sedimentando uma série de estruturas políticas e econômicas inerentemente desiguais (Gunder Frank, 2010, p. 8). Ora, o próprio modelo de 'modernização' e 'desenvolvimento' proposto na teoria de Rostow decorreria em um aprofundamento dessas desigualdades (ibidem, p. 15).

Dentre as diversas abordagens marxistas do 'Sul Global' à questão da desigualdade internacional, optamos por priorizar a análise do neocolonialismo feita por Kwame N'Krumah (que além de intelectual, foi o primeiro presidente da Gana independente), bem como as análises e prescrições propostas pela Teoria Marxista da Dependência (TMD). A seleção da obra de N'Krumah (1967) deve-se à sua relação direta com o contexto de descolonizações e independência em pauta nesse artigo. A priorização dos textos de André Gunder Frank (2010 [1966]) e Theotonio dos Santos (2011 [1970]) como representantes da TMD deve-se à primazia das abordagens desses autores em muitas das discussões em Relações Internacionais ${ }^{12}$ (Hage, 2013, p. 125). Como ponto em comum, ambas as abordagens convergem no apontamento de um desenvolvimento desigual inerente ao capitalismo, do qual resultam as desigualdades sistêmicas entre os países do centro e da periferia global.

Nesse sentido, tanto N'Krumah (1967) quanto Dos Santos (2011, p. 6-7) e Gunder Frank (2010, p. 8) avaliam que os níveis de desenvolvimento, industrialização e bem-estar social verificados nos países do Norte são um resultado direto da manutenção histórica e estrutural dos países do Sul em condições de dependência e subdesenvolvimento. Também é comum à denúncia ao neocolonialismo (N'Krumah) e à dependência (Dos Santos e Gunder Frank) o rechaço às prescrições para a superação das desigualdades advogadas por autores e atores do Norte Global. Nesse sentido, N'Krumah (1967), por exemplo, aponta que as diversas formas de 'ajuda externa', bilateral ou multilateral, são estratégias para a manutenção da subordinação dos países periféricos aos monopólios financeiros imperialistas internacionais.

André Gunder Frank (2010, p. 15-17), em sentido semelhante, questiona a 'importação' de modelos de modernização econômica etapistas/capitalistas como solução para a desigualdade e pobreza nos países periféricos. Para o autor, a quem se soma Dos Santos (2011, p. 16), a replicação desses modelos no 'Terceiro Mundo' geraria apenas o enriquecimento das elites nacionais e internacionais às custas da superexploração da mão de obra periférica. Diante desse

\footnotetext{
${ }^{12}$ De fato, a Teoria da Dependência - mesmo em sua vertente marxista - é composta por variadas inflexões e matizes teóricos. Em geral, prevalece nas RI uma abordagem centrada no trabalho de Fernando Henrique Cardoso e Enzo Faleto, que não se insere na perspectiva marxista à teoria da dependência (Martins; Valencia, 2001). Mesmo na TMD, como aponta Fernando Correa Prado (2011), há uma série de divergências, muitas vezes relacionadas com a maior aceitação e publicização de algumas vertentes teóricas em detrimento de outras.
} 
cenário, Gunder Frank (2010, p. 17) urge por interpretações socio-históricas que gerem soluções coerentes com as especificidades locais de cada um dos países terceiro-mundistas. Theotonio dos Santos (2011, p. 16-17), por sua vez, assume uma via mais radical. O autor rejeita as propostas de promoção do desenvolvimento feitas por organismos internacionais, afirmando que apenas a revolução socialista poderia romper com a dependência sistêmica enfrentada pelos países periféricos.

Tanto a denúncia do neocolonialismo quanto a da dependência resultam de esforços teóricos inéditos a partir do Sul Global para os problemas do Sul Global. Por um lado, essas abordagens críticas de cunho marxista foram assertivas em suas análises da relação intrínseca entre desenvolvimento e subdesenvolvimento numa economia mundial capitalista, inerentemente perpetuadora de desigualdades. Por outro, ambas as perspectivas falharam nas prescrições políticas que fizeram para a solução desse problema. Dos Santos (2011), por exemplo, ignorou a ausência de uma hegemonia ideológica suficientemente capaz de garantir a aquiescência e adesão das massas a potenciais movimentos revolucionários na América Latina. N'Krumah (1967), por sua vez, propôs medidas de superação do subdesenvolvimento que, em última instância, reforçam os marcos capitalistas criticados por ele: a industrialização, modernização agrícola e criação de grandes empresas voltadas para o comércio exterior, através da promoção da integração africana.

Não obstante, algumas das proposições teóricas desses autores do Sul Global acabaram sendo incorporadas em importantes processos na política internacional. Como ressalta Patrícia Leite (2011, p. 34-36), processos como a fundação da Comissão Econômica para a América Latina e o Caribe (CEPAL), do Movimento dos Não-Alinhados (MNA) e as reivindicações terceiromundistas por uma Nova Ordem Econômica Internacional (NOEI) foram fortemente influenciados por pressupostos teóricos acerca do neocolonialismo e da dependência. Não obstante, grande parte desses movimentos acabou sendo cooptado para a esfera analítica e argumentativa de teorias do Norte Global, como o liberalismo econômico e neoliberalismo institucional (Krasner, 1985, p. 13).

Dada essa primazia de abordagens economicistas e liberais à questão da emergência do Terceiro Mundo e da questão da desigualdade na agenda internacional, autores de outras abordagens teóricas nas $\mathrm{RI}$ começam a reagir. Um exemplo paradigmático nesse sentido é o de Stephen Krasner (1985), que propõe uma abordagem realista às reivindicações terceiro-mundistas por uma Nova Ordem Econômica Internacional (NOEI). Na perspectiva do autor, as abordagens liberais estariam equivocadas ao atribuir a esse movimento uma alçada estritamente econômica e a antevisão de uma suposta "nova moral" na política internacional (Krasner, 1985, p. 13-14).

Pelo contrário, Krasner (1985, p. 14) defende que as reivindicações pela NOEI seriam uma manifestação da mesma lógica que, segundo grande parte dos realistas, move todos os Estados em suas interações no sistema internacional: a maximização do poder e busca pela integridade política e territorial. Assim, a ação conjunta dos Estados do Terceiro Mundo para tentar modificar as regras de orientação liberal e mercadológica dos regimes internacionais vigentes não seriam o prenúncio de nenhuma "nova moral" na política mundial. Seria, mais propriamente, a 
materialização de um cálculo racional de ação para a redução da vulnerabilidade externa e aumento da incidência terceiro-mundista sobre processos decisórios na política internacional (Krasner, 1985, p. 11).

Para Krasner (1985, p. 30-32), portanto, a desigualdade internacional é um problema inerentemente político, relacionado à distribuição desigual da capacidade de controle e poder no sistema internacional. Tal distribuição desigual de poder poderia resultar em ameaça à sobrevivência dos Estados periféricos, o que justificaria a articulação entre eles para pautar conjuntamente questões como a Nova Ordem Econômica Internacional (NOEI). Sendo um problema eminentemente político, a desigualdade internacional exigiria soluções igualmente políticas. Nesse sentido, Krasner (ibidem) propõe a continuidade da articulação Sul-Sul para a modificação de regimes internacionais desiguais. Além disso, o autor sugere que o ideal seria uma redução das relações Norte-Sul apenas para questões estritamente necessárias, de modo a evitar atritos e garantir a estabilidade do sistema (ibidem, p. 32).

Por um lado, a capacidade de agência e resistência que Krasner (1985, p. 28) — ainda que teorizando no Norte - atribui aos países do Sul, é um ponto importante de sua análise. Trata-se de uma perspectiva que, apesar de compartilhar do realismo estrutural de Kenneth Waltz (1979), prevê uma maior relevância, incidência e agenciamento dos países do Terceiro Mundo na política internacional. Além disso, é uma perspectiva que retira a atuação terceiro-mundista da esfera estritamente econômica priorizada pelas abordagens (neo)liberais - como a de Robert Keohane (1984) —, enfatizando a sua dimensão política.

Não obstante, ao priorizar uma abordagem realista estrutural focada estritamente nos Estados e no sistema erigido por eles, Krasner (1985) acaba por ignorar a ação e incidência de outros importantes atores internacionais sobre a questão da desigualdade. Um exemplo seriam os monopólios financeiros e corporações transnacionais, cuja ação neocolonizadora é denunciada por N'Krumah (1967). Outro, seriam as resistências às desigualdades perpetuadas pela ordem internacional liberal a partir de outros atores que não os Estados, como ONGs e movimentos sociais. Além disso, apesar de reconhecer a relevância da incidência de países do Terceiro Mundo na política internacional, Krasner só a concebe nos termos previstos para a ação dos Estados na teoria realista (maximização de poder, garantia da sobrevivência e estabilidade sistêmica), desconsiderando outras alternativas e possibilidades.

Em sentido em certa medida divergente do de Stephen Krasner (1985), mas em linha com a desconsideração das possibilidades de uma ação criativa dos países terceiro-mundistas na política internacional, estão as considerações de Robert Tucker (1977). Tucker (1977) também olha, a partir do Norte Global, para a emergência do Terceiro Mundo e da questão da desigualdade como tópicos em evidência nas Relações Internacionais no período em que escreve. Porém, diferente de Krasner (1985), Tucker (1977, p. 54) desconsidera a capacidade de agência dos países do Terceiro Mundo como vozes ativas e propositivas de suas próprias pautas nas instâncias internacionais. 
Assim, o autor identifica o surgimento de uma "nova sensibilidade internacional" entre as elites políticas e intelectuais dos países desenvolvidos e industrializados (Tucker, 1977, p. 54-55). Tal "sensibilidade" seria caracterizada pelo reconhecimento da "responsabilidade moral" desses países de agir coletivamente para aliviar a pobreza e a desigualdade em países 'subdesenvolvidos' e não-industrializados (ibidem). Ora, a reforma e o alívio das desigualdades internacionais passa a ser atribuída como responsabilidade das próprias elites e países que, como indicam as proposições da Teoria Marxista da Dependência, têm há séculos se beneficiado do sistema que as perpetua. Desqualifica-se, assim, o potencial de os próprios atores e países do Terceiro Mundo proporem suas agendas de afronte às desigualdades internacionais.

Dessa forma, paradoxalmente, a proposta de Tucker (1977) de combate às desigualdades acaba por introduzir uma nova desigualdade ao já extenso rol de inequidades entre o Norte e o Sul Global. Retira-se dos países do Terceiro Mundo a possiblidade de propor e promover suas próprias agendas e reivindicações. Pelo contrário, reforça-se uma dependência terceiro-mundista com relação ao assistencialismo paternalista eventualmente provido pelos países desenvolvidos e industrializados. Tal perspectiva, incialmente avançada por Tucker (1977), repercutiu em trabalhos mais recentes de importantes teóricos da filosofia política, Relações Internacionais e do direito internacional.

Um exemplo paradigmático nesse sentido é um dos últimos trabalhos publicados por John Rawls (2000), no qual o autor se dedica a pensar em questões de direito e 'justiça' em escala internacional. Para Rawls (2000, p. 106), haveria um "dever de assistência" dos países "bemordenados" (desenvolvidos) para com os países "fora-da-lei" (subdesenvolvidos). Nesse sentido, o autor identifica a desigualdade como uma questão inerentemente política e, mais especificamente, institucional. Assim, Rawls (2000, p. 106) defende que alguns países não logram obter o progresso econômico porque não são capazes de se adequar aos imperativos das instituições liberais. A solução para a desigualdade internacional, portanto, também deve ser política/institucional: a promoção de democracias liberais e de padrões civilizatórios ocidentais em direção a sociedades não-ocidentais (ibidem, p. 116-120).

De maneira semelhante a Rostow (1974), Rawls (2000, p. 116-120) acredita que é só através dessa adequação aos padrões da 'civilização ocidental' que os países do Sul Global poderão lograr atingir o seu próprio desenvolvimento. Assim, também de forma similar a Rostow (1974), o autor acaba por ignorar a relação intrínseca entre o desenvolvimento dos países "bemordenados" e de suas instituições liberais, por um lado, e a marginalização dos Estados "fora-dalei”, por outro. Como lembram os teóricos marxistas-dependentistas, ambos os processos são parte de uma mesma história de exploração sistêmica e estrutural perpetuada pelo advento do capitalismo como economia mundial (Dos Santos, 2011, p. 6-7; Gunder Frank, 2010, p. 8). Além disso, Rawls (2000) reflete uma leitura orientalista e eurocêntrica de mundo, atribuindo características pejorativas a países e regiões do mundo que não se adequam aos padrões institucionais ocidentais e europeus, inerentemente assumidos como 'ideais' e 'universais' (Inayatullah; Blaney, 2004, p. 106-111). 
Críticas parecidas ao pensamento de John Rawls (2000) são compartilhadas por outros autores contemporâneos que, sem embargo, também fazem proposições de cunho paternalista. É o caso, por exemplo, de Thomas Pogge (2001). Pogge (2001, p. 11-12) reconhece que a intensificação das desigualdades internacionais é resultado das dinâmicas de funcionamento da "nova ordem econômica global" neoliberal, conforme instituída pelos países ricos via instituições como o Fundo Monetário Internacional (FMI), o Banco Mundial e a Organização Mundial do Comércio (OMC). Sendo assim, o autor propõe que a solução para os problemas da pobreza e da desigualdade internacional seria o reconhecimento, por parte dos países ricos, de sua responsabilidade moral pela perpetuação dessas mazelas (ibidem).

Mais do que reconhecer o seu papel, Pogge (2001, p. 14) advoga que os países ricos do Norte Global deveriam se comprometer com a destinação de 1 à $2 \%$ de seus Produtos Internos Brutos (PIBs) anuais para políticas de combate à desigualdade e pobreza internacionais. Contraditoriamente, no entanto, tais políticas deveriam visar justamente uma melhor integração dos países pobres à ordem econômica global neoliberal, cujo funcionamento promove e intensifica a sua pobreza e desigualdade. Ademais, ao apostar no voluntarismo paternalista dos países ricos para com os pobres, Pogge (2001) desconsidera o fato de que a manutenção da condição de desenvolvimento/supremacia dos países ricos muitas vezes depende fundamentalmente da continuidade dos países pobres na condição de subdesenvolvimento/subordinação.

Finalmente, Charles Beitz (2001) também apresenta uma prescrição paternalista de combate à desigualdade internacional, embora o faça em termos distintos aos propostos por Pogge (2001). Primeiramente, Beitz (2001, p. 101-102) contraria a proposição inocente de uma distribuição global de recursos materiais, uma vez que isso exigiria um nível de mobilização política dificilmente alcançável no cenário internacional. O autor também se posiciona contrário às perspectivas que veem na adequação das estruturas políticas domésticas a determinados padrões liberais a única estratégia possível para o combate à desigualdade (Beitz 2001, p. 102). Ainda assim, Beitz (2001, p. 109-110) aponta a necessidade de uma ação transnacional para promover medidas de combate à desigualdade, dentre elas o empoderamento e fomento à capacidade de agência local.

Desse modo, as proposições de Beitz (2001) acabam reproduzindo um tipo de narrativa que, ao ressaltar medidas voltadas para a capacidade de agência local, acabam por 'desresponsabilizar' atores e estruturas internacionais e seu peso na produção e reprodução de desigualdades sistêmicas (Chandler, 2013, p. 30-32). Além disso, reproduzem uma noção de "fardo do homem branco" (white men burden) presente também nas abordagens de Tucker (1977), Rawls (2000) e Pogge (2001) ao atribuírem uma responsabilidade paternalista dos países 'desenvolvidos/civilizados' sobre os 'subdesenvolvidos/incivilizados'. Ora, para Beitz (2001), mesmo o empoderamento de agentes locais exigiria uma ação paternalista conduzida 'desde fora' para se concretizar.

Em perspectivas mais recentes formuladas no Norte Global acerca das desigualdades internacionais, segue-se reproduzindo aspectos problemáticos das abordagens aqui apresentadas. Tanto uma suposta necessidade de adequação dos países do Sul Global a padrões 
econômicos e institucionais próprios do ocidente/Norte-Global quanto a apresentação desses padrões como 'universais' são elementos frequentes. Um exemplo nesse sentido é a perspectiva apresentada por François Bourguignon (2015). Bourguignon (2015, p. 34) reconhece que a emergência do Terceiro Mundo entre as décadas de 1940-1960 foi um processo que trouxe a questão das desigualdades internacionais e globais ${ }^{13}$ como tema central de debates teóricos e discussões políticas desde então. Não obstante, em suas prescrições, o autor segue reproduzindo a necessidade de adequação terceiro-mundista aos padrões tecnológicos e modelo de desenvolvimento dos países industrializados como forma de gerar crescimento econômico e, por essa via, superar as desigualdades (Bourguignon, 2015, p. 34).

Em síntese, portanto, temos algumas tendências gerais verificadas entre as respostas teóricas do Norte e do Sul Global à emergência do Terceiro Mundo e da questão da desigualdade na política internacional. Grosso modo, as perspectivas teóricas do Sul Global aqui analisadas enfatizam a relação indissociável entre as condições de 'subdesenvolvimento' dos países terceiromundistas e 'desenvolvimento' dos países centrais. Tal relação é atribuídas às dinâmicas e estruturas historicamente consolidadas no âmbito de uma economia mundial capitalista. Como desafio central, as perspectivas do Sul Global encontram a proposição de alternativas factíveis a esse paradigma de desigualdades.

Nas perspectivas formuladas no Norte Global, tende-se a apontar a questão da desigualdade como fruto de uma incapacidade terceiro-mundista em se adequar a padrões e modelos políticos, econômicos e institucionais notadamente ocidentais. Como corolário, geralmente tem-se o apontamento de uma 'responsabilidade moral' de os países ricos ocidentais 'ajudarem' de alguma forma aqueles que mais sofrem com as mazelas da desigualdade. Algumas das perspectivas, como em Beitz (2001), Pogge (2001) e Rawls (2000), negam a abertura para uma vocalização das reivindicações terceiro-mundistas desde os próprios países do Sul, sem a necessidade de algum tipo de mediação ou intervenção por atores do Norte Global. Outras, como a leitura realista de Stephen Krasner (1985), buscam assimilar as reivindicações terceiromundistas à lógica imperante na política entre as Grandes Potências, negando de maneira semelhante a proposição de alternativas a essa lógica que possam emergir a partir das experiências e proposições do Sul Global.

\section{CONSIDERAÇÕES FINAIS}

A partir das reflexões apresentadas ao longo do artigo, notamos que a emergência dos países do Terceiro Mundo e, consequentemente, da questão da desigualdade no cenário internacional, gerou diagnósticos e prescrições teóricos distintos no Norte e no Sul Global. Pensando essa questão à luz da "geopolítica do conhecimento", conceito introduzido nas considerações iniciais do texto, concluímos que o lugar geográfico e o lugar epistêmico do sujeito

${ }^{13}$ Para uma distinção entre ambas, na perspectiva do autor, ver (Bourguignon 2015, p. 9). 
teorizador são indissociáveis entre si, e influenciam diretamente no resultado de suas análises e prescrições teóricas e políticas.

Desse modo, por um lado apresentamos um exemplo das manifestações da "geopolítica do conhecimento" em um contexto histórico específico, a emergência do Terceiro Mundo com as descolonizações entre as décadas de 1940-1960. Por outro lado, mas de maneira relacionada, buscamos enfatizar como esse processo inerentemente político tem também uma dimensão epistêmica, notada nas abordagens divergentes entre o Norte e o Sul Global.

De maneira esquemática, mas não totalizante, nota-se nas perspectivas a partir do Sul uma avaliação do problema da desigualdade como uma questão fundamentalmente econômica — resultante da dinâmica inerentemente desigual do sistema capitalista mundial — cuja solução deve ser política, com a ruptura revolucionária desse sistema. Já as abordagens a partir do Norte Global apresentam matizes distintas. Nas abordagens do realismo estrutural, por exemplo, a desigualdade é apresentada como um problema político que exige soluções políticas. Nos enfoques liberais, por outro lado, há autores que identificam a desigualdade internacional como um problema político com solução política (instituições liberais em Rawls), ou tanto político quanto econômico com solução política (ação transnacional em Beitz) ou política e econômica (distribuição de recursos materiais em Pogge).

Fundamentalmente, nota-se que - com a exceção, em certa medida, de Krasner (1985) - as perspectivas do Norte global assumem vieses paternalistas e de promoção da adequação dos países do Sul à ordem política e econômica do sistema mundial capitalista liberal instituído pelas potências ocidentais, por mais que por vezes essa mesma ordem seja identificada como fonte de importantes desigualdades internacionais. As perspectivas a partir do Sul Global, pelo contrário, prescrevem o protagonismo e autonomia dos países terceiro-mundistas e a integração entre eles para promover mudanças e rupturas na ordem global.

Conforme sugerido na seção anterior, as propostas apresentas a partir do Sul carecem de factibilidade, ou ao menos de prescrições políticas mais claras de como se concretizar. As feitas a partir do Norte, apesar de diversas, convergem na negação da vocalização de perspectivas e proposições feitas de maneira autônoma e independente pelos países do Sul Global. Feita essa análise, concluímos indicando a necessidade de se abrir avenidas de investigação comparando a incidência dos lugares epistêmicos mas manifestações teóricas tanto do Norte quanto do Sul Global mediante a cenários internacionais mais contemporâneos, como a onda neoliberal da década de 1990 ou o 'ciclo progressista' inaugurado em alguns dos países ditos 'terceiromundistas' em inícios do século XXI.

Outra futura linha de investigação que se desprende a partir daqui diz respeito a uma dimensão mais aprofundada da "geopolítica do conhecimento". Se, como argumentamos ao longo do texto, as abordagens do Norte Global invisibilizam e silenciam proposições alternativas e criativas à questão da desigualdade a partir do Sul Global, que alternativas são essas? Quais são os atores que as enunciam? Isso implicaria um questionamento aos próprios Estados terceiromundistas como 'sujeitos' priorizados na análise, bem como aos limites de uma ação crítica e 
'alterativa' em uma ordem mundial carregada de princípios, valores e entendimentos eurocêntricos. Um engajamento mais aprofundado com tais questões, portanto, é um eventual encaminhamento para um trabalho posterior.

* Recebido em: 26 de maio de 2019

Aprovado em: 18 de julho de 2019.

\section{REFERENCIAS}

BEITZ, Charles. Does Global Inequality Matter? Metaphilosophy, v. 32, p. 95-112, 2001.

BLANEY, David; TICKNER, Arlene. Worlding, Ontological Politics and the Possibility of a Decolonial IR. Millennium: Journal of International Studies, v. 45, n. 3, p. 1-19, 2017.

BOURGUIGNON, François. The globalization of inequality. Princeton University Press, 2015.

CHANDLER, David. Peacebuilding and the politics of non-linearity: rethinking 'hidden' agency and 'resistance'. Peacebuilding, v. 1, n. 1, p. 17-32, 2013.

DOS SANTOS, Theotonio. A estrutura da dependência. Revista da Sociedade Brasileira de Economia Política, São Paulo, v. 30, p. 5-18, 2011.

ESCOBAR, Arturo. La invención del Tercer Mundo: Construcción y deconstrucción del desarrollo. Caracas: Fundación Editorial el perro y la lana, 2007.

GUITARD, Odete. Bandung y el despertar de los pueblos coloniales. Buenos Aires: Editorial Universitaria de Buenos Aires, 1962.

GUNDER FRANK, André. 'The Development of Underdevelopment', in: C. Chew e P. Lauderdale (eds.). Theory and Methodology of World Development: The writings of Andre Gunder Frank. New York: Palgrave Macmillan, p. 7-18, 2010. (Capítulo 1).

HAGE, J. A. A Teoria da Dependência: Uma Contribuição aos Estudos de Relações Internacionais. Revista Política Hoje, v. 22, n. 1, p. 106-136, 2013. Disponivel em: <https://periodicos.ufpe.br/revistas/politicahoje/article/viewFile/3776/3080>. Acesso em: 18 jul. 2019.

HOFFMANN, S. An American Social Science: International Relations. Daedalus, v. 106, n. 3, p. 41-60, 1977.

INAYATULLAH, N.; BLANEY, D. International relations and the problem of difference. New York: Routledge, 2004.

KEOHANE, R. After Hegemony: Cooperation and Discord in the World Political Economy. Princeton: Princeton University Press, 1984. 
KRASNER, Stephen. Structural Conflict: The Third World against Global Liberalism. Berkeley: University of California Press, 1985.

KRISHNA, S. Globalization and Postcolonialism: Hegemony and Resistance in the TwentyFirst Century. Lanham: Rowman \& Littlefield, 2009.

KUBÁLKOVÁ, Vendulla; CRUICKSHANK, Albert. International Inequality. London: Croom Helm, 1981.

LEITE, Patrícia Soares. O Brasil e a cooperação sul-sul em três momentos de política externa: os governos Jânio Quadros/João Goulart, Ernesto Geisel e Luiz Inácio Lula da Silva. Brasília: Fundação Alexandre de Gusmão, 2011.

N'KRUMAH, Kwame. Neocolonialismo: O Último Estágio do Imperialismo. Rio de Janeiro: Civilização Brasileira, 1967.

MARTINS, C. E.; VALENCIA, A. S. Teoria da dependência, neoliberalismo e desenvolvimento: reflexões para os 30 anos da teoria. Lutas sociais, v. 7, p. n.p., 2001. Disponivel em: <https://revistas.pucsp.br/index.php/ls/article/view/18781>. Acesso em: 18 jul. 2019.

MIGNOLO, W. Las geopolíticas del conocimiento y colonialidad del poder; [Entrevista concedida a] Catherine Walsh. Polis - Revista Latinoamericana, v. 4, p. 1-22, 2003.

MIGNOLO, W. Capitalismo y geopolítica del conocimiento. In: DUBE, S.; DUBE, I.; MIGNOLO, W. Modernidades coloniales: otros pasados, historias presentes. Ciudad de México: El Colegio de México, 2004. Cap. 10, p. 227-260.

MOHANTY, C. Feminism without Borders: Decolonizing Theory, Practicing Solidarity. Durham: Duke Univeristy Press, 2003.

POGGE, Thomas. Priorities of Global Justice. Metaphilosophy, v. 32, n. 1/2, p. 6-24, 2001.

PRADO, F. C. História de um não-debate: a trajetória da teoria marxista da dependência no Brasil. Comunicação \& Política, v. 22, p. 68-94.

RAWLS, John. The Law of Peoples. 2. ed. Cambridge: Harvard University Press, 2000.

ROSTOW, Walt Whitman. Etapas do desenvolvimento econômico: um manifesto nãocomunista. Rio de Janeiro: Zahar, 1974.

SHILLIAM, R. Non-Western thought and international relations. In: SHILLIAM, R. International Relations and Non-Western Thought: Imperialism, colonialism and investigations of global modernity. London: Routledge, 2011. Cap. 1, p. 1-11.

SMITH, S. The discipline of international relations: still an American social science? British Journal of Politics and International Relations, v. 2, n. 3, p. 374-402, 2000. 
TUCKER, Robert. The Inequality of Nations. New York: Basic Books, 1977.

WALTZ, Kenneth. Theory of International Politics. Reading: Addison-Wesley Publishing Company, 1979. 